\title{
RESEARCH
}

Open Access

\section{Prevalence and clinical significance of cardiovascular magnetic resonance adenosine stress-induced myocardial perfusion defect in hypertrophic cardiomyopathy}

Eun Kyoung Kim', Sang-Chol Lee ${ }^{1 *}$, Sung-A Chang ${ }^{1}$, Shin-Yi Jang ${ }^{1}$, Sung Mok Kim², Sung-Ji Park', Jin-Oh Choi', Seung Woo Park', Eun-Seok Jeon ${ }^{1}$ and Yeon Hyeon Choe ${ }^{2^{*}}$

\begin{abstract}
Background: Hypertrophic cardiomyopathy (HCM) is thought to be associated with microvascular dysfunction. Adenosine stress-perfusion cardiovascular magnetic resonance imaging (CMR) is a sensitive method for assessing microvascular perfusion abnormalities. We evaluated the prevalence and clinical characteristics of HCM patients with adenosine-induced perfusion defects on CMR.

Methods: Among 189 consecutive patients with HCM who underwent adenosine-stress perfusion CMR, 115 patients who had clinical, echocardiography, 24-h Holter monitoring and treadmill exercise test data were analyzed. We calculated myocardial perfusion ratio index from the intensity-over-time curve to quantify perfusion defects. The presence and extent of the stress-induced perfusion defect were compared with clinical characteristics, presence and extent of late gadolinium enhancement (LGE), left ventricular (LV) mass index and volume, presence of nonsustained ventricular tachycardia (NSVT) and results of treadmill exercise test.

(Continued on next page)
\end{abstract}

\footnotetext{
*Correspondence: sc.lea@samsung.com; yh.choe@samsung.com

${ }^{1}$ Division of Cardiology, Department of Medicine, Samsung Medical Center, Heart Vascular Stroke Institute, Sungkyunkwan University School of Medicine, \#81 Irwon-ro, Gangnam-gu, Seoul 06351, South Korea

${ }^{2}$ Department of Radiology and Cardiovascular Imaging Center, Samsung Medical Center, Sungkyunkwan University School of Medicine, 50 Irwon-ro, Gangnam-gu, Seoul 06351, South Korea
}

(c) The Author(s). 2020 Open Access This article is licensed under a Creative Commons Attribution 4.0 International License, which permits use, sharing, adaptation, distribution and reproduction in any medium or format, as long as you give appropriate credit to the original author(s) and the source, provide a link to the Creative Commons licence, and indicate if changes were made. The images or other third party material in this article are included in the article's Creative Commons licence, unless indicated otherwise in a credit line to the material. If material is not included in the article's Creative Commons licence and your intended use is not permitted by statutory regulation or exceeds the permitted use, you will need to obtain permission directly from the copyright holder. To view a copy of this licence, visit http://creativecommons.org/licenses/by/4.0/ The Creative Commons Public Domain Dedication waiver (http://creativecommons.org/publicdomain/zero/1.0/) applies to the data made available in this article, unless otherwise stated in a credit line to the data. 
(Continued from previous page)

Results: The mean age of enrolled patients was $51.8 \pm 11.3$ years. Most patients were asymptomatic except 25 subjects presented with New York Heart Association Class II dyspnea and 16 patients with atypical non-exertional chest discomfort. LGE was present in 103 (89.6\%) subjects. Adenosine stress-induced perfusion defects were present in $48(42 \%)$ subjects. None of the perfusion defects corresponded with a single or multiple coronary artery territories, showing a multiple patchy pattern in 24 (50.0\%), a concentric subendocardial pattern in 20 subjects (41.7\%), and as a single blot-like defect in the remaining 4 (8.3\%). A perfusion defect was associated with NSVT, LV apical aneurysm, higher LV mass index, and higher LGE volume on univariate analysis. Multivariate analysis revealed female gender $(P=0.008)$, presence of apical aneurysm and NSVT ( $P=0.036$ and 0.047 , respectively), and LV mass index $(P=0.022)$ to be independently associated with adenosine stress-induced perfusion defects.

Conclusions: In patients with HCM, adenosine-stress perfusion defects on CMR are present in more than $40 \%$ of subjects. This perfusion defect is associated with NSVT, higher LV mass index, and apical aneurysms. The prognostic value of this finding needs further elucidation.

Keywords: Cardiomyopathy, hypertrophic, Magnetic resonance imaging, Myocardial perfusion imaging, Myocardial ischemia, Microcirculation

\section{Background}

Hypertrophic cardiomyopathy (HCM) is a primarily myocardial disease with inappropriate growth and disarray of myocardial cells as well as interstitial fibrosis [1]. Since its original description, HCM has also been thought to be associated with myocardial ischemia due to microvascular dysfunction [2-5]. Nevertheless, in vivo studies of myocardial perfusion abnormalities in HCM are rare [6-8].

Cardiovascular magnetic resonance (CMR) has generated a great interest for assessing the myocardial abnormalities in HCM, especially for the presence of fibrosis in the hypertrophied myocardium with late gadolinium enhancement (LGE) in the myocardium [9-14]. Adenosine-stress perfusion CMR is a highly sensitive method for assessing myocardial perfusion abnormalities [15-17], and it has also been found to be useful for detecting perfusion abnormalities in suspected coronary artery disease as well as with microvascular dysfunction [18].

Our study sought to evaluate the frequency of microvascular perfusion abnormality in HCM assessed by adenosine-stress perfusion CMR and to elucidate its relationship with clinical characteristics as well as risk factors associated with HCM.

\section{Methods}

\section{Study population}

We prospectively enrolled 189 consecutive subjects diagnosed with HCM between December 2008 and November 2012 who underwent CMR with adenosine stress perfusion study that were included in the HCM registry of our cardiovascular imaging center as part of a research protocol. The diagnosis of HCM was based on the conventional guideline [19]; echocardiographic evidence of significant left ventricular (LV) hypertrophy which was defined as LV wall thickness of $\geq 15 \mathrm{~mm}$ in the absence of any other significant cardiac or systemic disease that could lead to concentric LV hypertrophy. Exclusion criteria were: Presence of cardiac or systemic disease causing concentric hypertrophy or increased wall thickness (e.g. aortic stenosis, amyloidosis, or systemic hypertension); age $<18$ or $>75$; typical chest pain of angina pectoris and documented coronary artery disease; symptoms of moderate to severe heart failure (New York Heart Association (NYHA) functional class III or IV); known ischemic coronary disease; and contraindications for CMR; Subjects whose exercise electrocardiogram (ECG) results showed significant ST segment changes (down-sloping or horizontal ST segment depression of more than $1 \mathrm{~mm}$, ST segment elevation, or development of left bundle branch block) were excluded from the analysis. The study protocol was reviewed and approved by the institutional ethics review board of our institute.

\section{Clinical information}

Clinical information including history of syncope or heart failure, and family (defined as first-degree relative) history of HCM or sudden cardiac death were collected, as well as cardiac risk factors. Twenty-four-hour ECG monitoring and symptom-limited treadmill exercise stress test were performed within a month of the CMR in subjects who were available for the tests. Results of the treadmill exercise test analyzed were; duration of exercise, adequacy of blood pressure response to exercise (defined as blood pressure increase of $20 \mathrm{mmHg}$ or more), and presence of significant ST segment changes during exercise. The presence of LV outflow tract obstruction was assessed by echocardiography, with a characteristic late peaking velocity of $>3 \mathrm{~m} / \mathrm{sec}$ as the definition of flow obstruction at rest or with Valsalva maneuver. 


\section{CMR protocol}

CMR was performed using a $1.5 \mathrm{~T}$ CMR system (Avanto B15, Siemens Healthineers, Erlangen, Germany) with a standardized CMR protocol with subjects in the supine position using a 32-element-phased-array cardiac coil. In detail, breath-held cine-CMR images of the whole heart were obtained with a ECG-gated balanced steady-state free precession sequence (echo time/repetition time/flip angle $1.31 \mathrm{~ms} / 3.09 \mathrm{~ms} / 72^{\circ}$, spatial resolution $1.72 \times$ $1.29 \times 6 \mathrm{~mm}^{3}, 30$ heart phases) to evaluate the LV function and myocardial mass. After the 2-chamber, 3chamber, and 4-chamber long-axis views were obtained, short-axis stack cine-CMR images were obtained to cover the whole LV from the apex to the base with a slice thickness of $6 \mathrm{~mm}$ with $4 \mathrm{~mm}$ gaps. Stress perfusion CMR was performed with a 3-min continuous intravenous infusion of adenosine with a rate of $140 \mu \mathrm{g} / \mathrm{kg} / \mathrm{min}$. After the 3-min infusion, $0.1 \mathrm{mmol} / \mathrm{kg}$ of gadobutrol (Gadovist, Bayer Healthcare, Berlin, Germany) was injected as a bolus application with a rate of $3.0 \mathrm{ml} / \mathrm{sec}$ followed by a $20 \mathrm{ml}$ saline flush. Four short-axis slices were obtained with TurboFLASH sequence without breath-hold for $1 \mathrm{~min}$ and the adenosine infusion was terminated subsequently. Fifteen minutes after termination of the adenosine infusion, an identical perfusion sequence was applied at rest. LGE images were obtained $10 \mathrm{~min}$ after the second contrast injection using a 2dimensional TurboFLASH phase-sensitive inversionrecovery sequence (echo time/repetition time/flip angle $3.6 \mathrm{~ms} / 8.14 \mathrm{~ms} / 25^{\circ}$, spatial resolution $2.08 \times 1.56 \times 6$ $\mathrm{mm}^{3}$, slice thickness $6 \mathrm{~mm}$, inversion time adjusted for each patient to obtained optimal nulling of normal myocardium) in short-and long-axis planes.

\section{CMR analysis}

CMR scans were visually interpreted by two experienced readers who were blinded to the clinical and laboratory data. In case of disagreement, a third experienced reader confirmed the findings. The types of HCM were categorized as septal, apical, septal and apical, concentric, and other. The LV end-diastolic and end-systolic volumes, ejection fraction, and mass were analyzed using commercialized software (CASS MRV CMR analysis software Version 3.3, Pie Medical Imaging B.V., Maastricht, Netherlands) by manually tracing the endocardial and epicardial contours in the short-axis stacks of enddiastolic and end-systolic images. For perfusion analysis, stress and rest perfusion scans were magnified and displayed and read simultaneously. The presence of perfusion defect was defined by regional hypoenhancements that persist for more than 10 frames after maximal myocardial enhancement [20]. Perfusion analysis of each myocardial segment was performed using the 16segment model excluding the apical cap (modified from the 17-segment model recommended by the American Society of Echocardiography) [21]. The perfusion defects were also analyzed for correspondence with a coronary artery territory (left anterior descending coronary artery: anterior or septal segments together with apical segments; left circumflex coronary artery: lateral segments; right coronary artery: inferior segments), and categorized as non-corresponding when the sites of the defect were dispersed without correspondence to any one or multiple coronary artery territories. For quantitative analysis of the perfusion defects, the 16 segments were individually analyzed using the same software as above by modification of previously described methods [22, 23]. In brief, after the intensity-over-time curves were generated for each segment and the LV cavity blood pool in each corresponding slice, the maximum upslope (intensity/ sec) of the myocardium were normalized to the LV cavity upslope to obtain myocardial perfusion ratio index (MPRI) for each segment. The MPRI were averaged for all myocardial segments. Myocardial LGE analysis was also performed using the 16-segment model with a cutoff value of signal intensities of over 6 standard deviations (SD) compared to the normal myocardial segment, as signal intensity of $6 \mathrm{SD}$ or more above remote myocardium has been shown to have the best accuracy to demonstrate histology-verified fibrosis in HCM and enables comparisons with recent major studies [4, 24-27]. When the sites that showed perfusion defects at stress overlapped with the sites with LGE, the perfusion defects were considered to be caused by the fibrotic tissue at the site, and thus rendered stress negative. When LGE was present, the boundaries of the sites showing LGE were manually traced and the volume was calculated with the same software. The extent of LGE was quantified as a percentage of the total LV myocardial volume. The presence of an LV apical aneurysm was also assessed and expressed as present or absent.

\section{Evaluation of epicardial coronary arteries}

Structural stenosis of the epicardial coronary arteries were evaluated in a proportion among the subjects in the stress CMR positive groups who agreed to receive the tests. Invasive coronary angiography was performed in 3 and coronary computed tomography angiography was performed in 21 subjects. All of the studies revealed normal or unremarkable findings of less than $10 \%$ diameter epicardial coronary artery stenosis.

\section{Statistical analysis}

The subjects were divided into two groups: stress CMR positive and negative. All analyses were performed with PASW statistics 18 (Statistical Package for the Social Sciences, International Business Machines, Inc., Armonk, New York, USA). The inter-observer 
agreement analysis between the original two readers was performed by obtaining the intraclass correlation coefficient (ICC, average and 95\% confidence interval) by reliability analysis. Chi-square association analysis was performed for evaluation of association of the stressinduced perfusion defects and the collected clinical information, type of HCM, the presence of LGE, and presence of apical aneurysm. Association between the stress-induced perfusion defect and LV volume, LV ejection fraction (LVEF), LV mass index, LGE volume, and LGE percentage was evaluated by the Mann-Whitney analysis. Multivariate analysis was performed with binary logistic regression analysis for evaluation of independent association of factors. Data are represented in frequency or mean \pm standard deviation, and a $P$ value of less than 0.05 was considered significant.

\section{Results}

\section{Clinical characteristics}

After exclusion of subjects according to the exclusion criteria, a total of 115 subjects were included in our analysis. Their mean age was $51.8 \pm 11.3$ years and male was predominant $(83.5 \%)$. A history of diabetes was present in $4(3.5 \%)$, current smoking in $30(26.1 \%)$, and 28 (24.3\%) were ex-smokers (defined as abstinence from smoking for at least 1 year). Twenty-five subjects presented with NYHA Class II dyspnea (21.7\%), 16 presented with atypical non-exertional chest discomfort (13.9\%), and the remaining were asymptomatic. History of syncope was present in 9 (7.8\%), and family history of HCM and sudden cardiac death was present in $8(7.0 \%)$ and $13(11.3 \%)$, respectively.

\section{Laboratory and echocardiographic findings}

Non-sustained ventricular tachycardia (NSVT) was detected in $11(10.7 \%)$ of the 103 subjects who received 24-h ECG monitoring. Treadmill exercise stress test was performed in 102 subjects, and the mean duration of exercise was $9.4 \pm 2.3 \mathrm{~min}$. Inadequate blood pressure response to exercise was detected in 24 subjects (23.5\%).

HCM was of septal type in 40 (34.8\%), septal/apical type in $32(27.8 \%)$, apical type in $28(24.3 \%)$, concentric type in $13(11.3 \%)$, and others in 2 (1.7\%). LV outflow obstruction with systolic anterior motion of the mitral valve on echocardiography was present in 31 (27.0\%) subjects.

\section{CMR findings}

None of the patients had an abnormal blood pressure response to adenosine (Table 1). None experienced substantial vasodilator or gadolinium-related adverse symptoms except mild chest discomfort (20.9\% of all patients) during the infusion of adenosine. Mean LV enddiastolic and end-systolic volume, LVEF, and LV mass
Table 1 Hemodynamic response and safety data during cardiovascular magnetic resonance (CMR) examination

\begin{tabular}{ll}
\hline & $N=115$ \\
\hline $\begin{array}{l}\text { Before adenosine infusion } \\
\text { Systolic blood pressure, } \mathrm{mmHg}\end{array}$ & $148 \pm 18$ \\
Diastolic blood pressure, $\mathrm{mmHg}$ & $76 \pm 12$ \\
Heart rate, beats per minute & $76 \pm 67$ \\
During adenosine infusion & \\
$\quad$ Systolic blood pressure, $\mathrm{mmHg}$ & $147 \pm 19$ \\
Diastolic blood pressure, $\mathrm{mmHg}$ & $75 \pm 12$ \\
Heart rate, beats per minute & $77 \pm 13$ \\
After CMR examination & \\
Systolic blood pressure, $\mathrm{mmHg}$ & $144 \pm 21$ \\
Diastolic blood pressure, mmHg & $72 \pm 12$ \\
Heart rate, beats per minute & $83 \pm 14$ \\
Chest discomfort during infusion, $\mathrm{n}(\%)$ & $24(20.9 \%)$ \\
\hline
\end{tabular}

index were $138.9 \pm 27.1 \mathrm{ml}, 39.4 \pm 12.4 \mathrm{ml}, 71.6 \pm 7.3 \%$, and $88.2 \pm 29.9 \mathrm{~g} / \mathrm{m}^{2}$, respectively. LGE was present in 103 (89.6\%) subjects, and mean LGE volume and percentage were $20.0 \pm 20.5 \mathrm{ml}$ and $11.6 \pm 8.9 \%$, respectively. An apical aneurysm was found in 13 (11.3\%) subjects.

Visually assessed stress-induced perfusion defects were present in $48(41.7 \%)$ patients. None of the defects corresponded with a single or multiple coronary artery territories, showing a multiple patchy pattern in $24(50.0 \%)$, a concentric subendocardial pattern in 20 subjects (41.7\%), and as a single blot-like defect in the remaining 4 (8.3\%) (Figs. 1, 2 and 3). The ICC for the visual assessment of stress-induced perfusion defects between the original two readers was 0.94 with a $95 \%$ confidence interval from 0.90 to 0.96 . On quantitative analysis, mildly significant difference in MPRI was found between the stress-positive group and the stress-negative group $(0.83 \pm 0.19$ vs. $0.94 \pm 0.30, p=0.046)$. However, when the stress-negative group was divided into two groups (no perfusion defect group and perfusion-defectcorresponding-to-LGE-site group), significant differences were found between the no perfusion defect group and the perfusion-defect-corresponding-to-LGE-site group $(1.12 \pm 0.46$ vs. $0.87 \pm 0.15, p<0.01)$, and also between the stress-positive group and the no perfusion defect group $(p=0.001)$. There was no significant difference in MPRI between the stress-positive group and the perfusion-defect-corresponding-to-LGE-site group.

\section{Difference in clinical and laboratory characteristics between stress-positive and negative groups}

There was no difference in age, gender ratio, frequency of history of diabetes, and frequency of current or exsmokers between the stress-positive and the stress- 

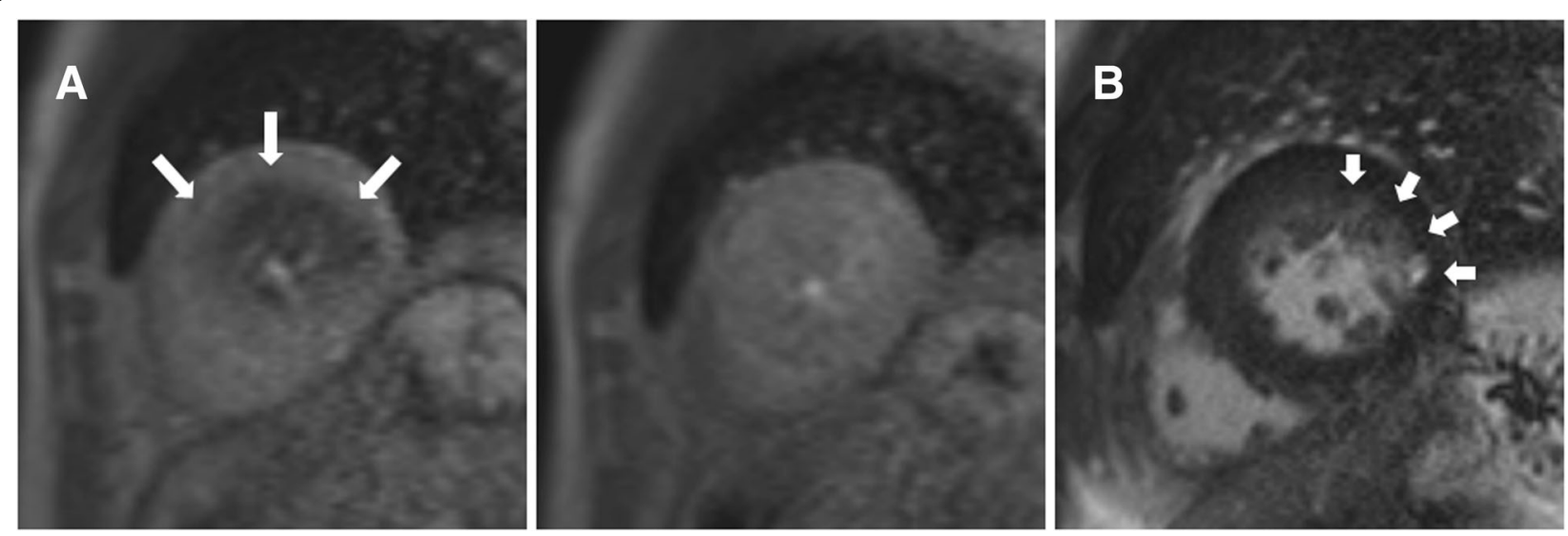

Fig. 1 Patchy adenosine stress-induced perfusion defects on cardiovascular magnetic resonance (CMR) and late gadolinium enhancement (LGE). a. Short-axis adenosine-stress perfusion images of the left ventricle at stress (left) and rest (right) show patchy reversible perfusion defects (large arrows) at the junction between midventricular and apical segments. b. LGE analysis by inversion recovery show LGE (small arrows) in midventricular segments that are separate from the stress perfusion image slices

negative groups. History of syncope and family history of sudden cardiac death or HCM were not different between the two groups either. Symptoms of dyspnea and atypical non-exertional chest pain were also not associated with positive results on stress perfusion (Table 2).

The type of HCM, exercise duration on treadmill exercise test, and frequency of LV outflow tract obstruction were not associated with the presence of stress-induced perfusion defects. NSVT on 24-h ECG monitoring was found more frequently in the stress positive group $(p=0.027)$, but exercise duration on treadmill test or the frequency of abnormal blood pressure response to exercise were not different between the two groups (Table 3).
Data from CMR are summarized in Table 4. Neither the LV volumes nor the LVEF showed any significant difference between the two groups. Mean LV mass index was significantly greater in the stress-positive group $(98.0 \pm$ 30.9 vs. $\left.81.3 \pm 27.3 \mathrm{~g} / \mathrm{m}^{2}, p=0.003\right)$. The presence or absence of LGE was not significantly different between the two groups, with 45 subjects (93.8\%) in the stress-positive group and 58 (86.6\%) subjects in the stress-negative group showing LGE. However, the presence of stress-induced perfusion defects was significantly associated with higher LGE volume and also with LGE volume percentage $(26.0 \pm 24.7$ vs. $15.6 \pm 15.6 \mathrm{ml}, p=0.012,14.1 \pm 9.9$ vs. $9.9 \pm 7.6 \%, p=0.015$, respectively). Apical aneurysm on CMR (Fig. 4) was found more frequently in the stress positive group (10 vs. 3 subjects, $p=0.006$ ).

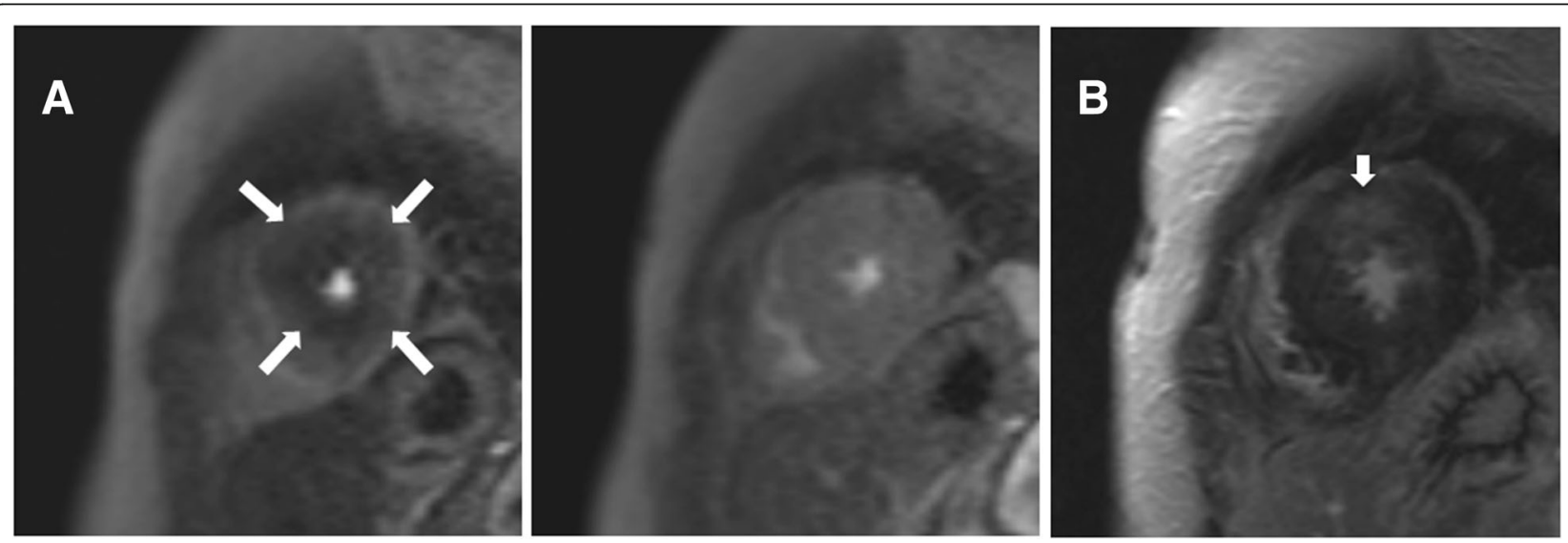

Fig. 2 Concentric adenosine stress-induced perfusion defect on CMR and LGE. a. Short-axis adenosine-stress perfusion images of the left ventricle at stress (left) and rest (right) show concentric reversible perfusion defects (large arrows) at the apical segments. b. LGE analysis by inversion recovery show focal LGE (small arrows) in the anterior apical segment. Most of the area with concentric perfusion defect shown on stressperfusion images do not overlap with the LGE area 

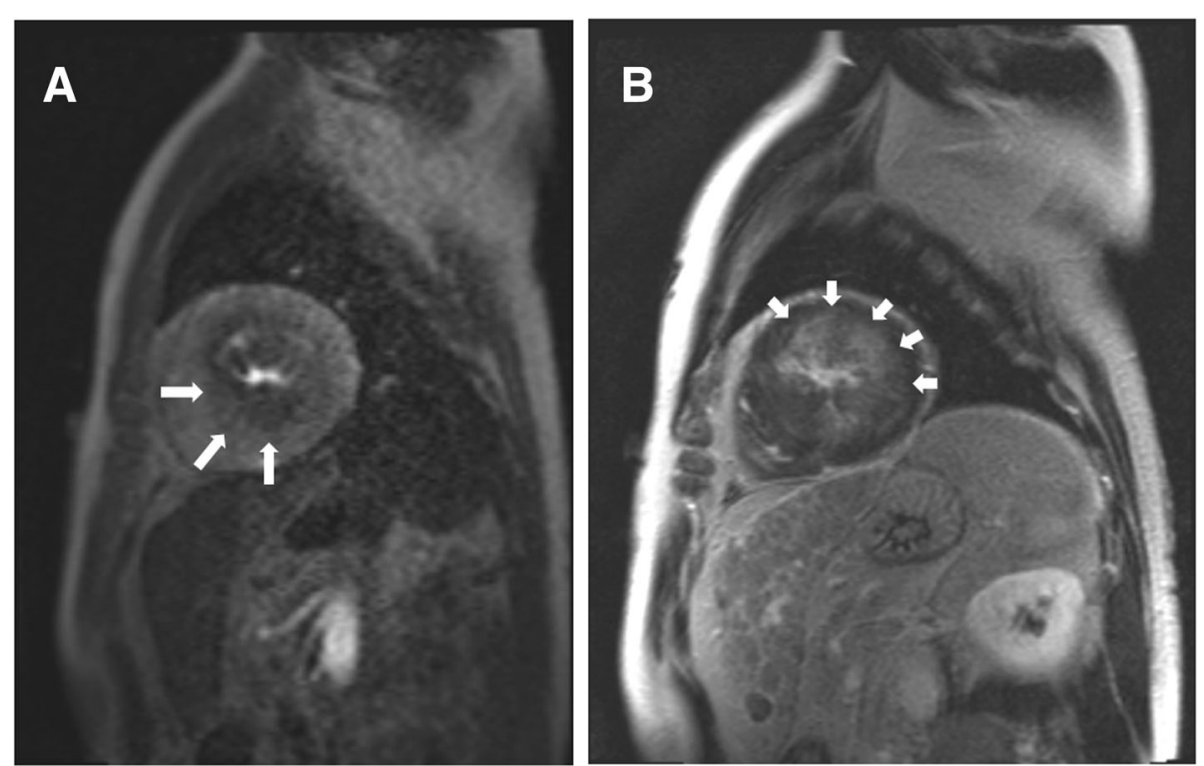

Fig. 3 Focal blot-like adenosine stress-induced perfusion defect on CMR and LGE. a. Short-axis adenosine-stress perfusion images of the left ventricle at stress show concentric reversible perfusion defects (large arrows) at the septal and inferior midventricular segments. b. LGE analysis by inversion recovery show patchy LGE (small arrows) in the anterior and lateral midventricular segments. Most of the area with focal perfusion defect shown on stress-perfusion images do not overlap with LGE area

Multivariate regression analysis revealed female gender (odds ratio [OR] with 95\% CI 8.33 [1.72-33.33], $p=$ $0.008)$, presence of apical aneurysm (5.58 [1.12-27.7], $p=0.036)$, NSVT on 24-h ECG (6.38 [1.03-39.63], $p=$ $0.047)$, and higher LV mass index (1.03 [1.00-1.06], $p=$ 0.022 ) to be independently associated with presence of stress-induced perfusion defects (Table 5).

Table 2 Comparison of clinical characteristics between CMR adenosine stress-positive and negative groups

\begin{tabular}{llll}
\hline Variables & $\begin{array}{l}\text { Stress positive } \\
(n=48)\end{array}$ & $\begin{array}{l}\text { Stress } \\
\text { negative } \\
(n=67)\end{array}$ & $P$ value \\
\hline Age in years & $50.6 \pm 11.6$ & $52.6 \pm 11.1$ & 0.34 \\
Male (\%) & $37(77.1)$ & $59(88.1)$ & 0.12 \\
Diabetes (\%) & $2(4.2)$ & $2(3.0)$ & 0.73 \\
$\begin{array}{l}\text { Atypical chest } \\
\text { pain (\%) }\end{array}$ & $5(10.4)$ & $11(16.4)$ & 0.36 \\
$\begin{array}{l}\text { NYHA class II } \\
\text { dyspnea (\%) }\end{array}$ & $13(27.1)$ & $12(17.9)$ & 0.24 \\
$\begin{array}{l}\text { History of syncope (\%) } \\
\text { Family history of }\end{array}$ & $3(6.3)$ & $6(9.0)$ & 0.60 \\
$\quad \begin{array}{l}\text { Sudden cardiac } \\
\text { death (\%) }\end{array}$ & $5(10.4)$ & $8(11.9)$ & 0.80 \\
$\quad$ HCM (\%) & $3(6.3)$ & $5(7.5)$ & 0.80 \\
Smoking & & $16(23.9)$ & 0.70 \\
$\begin{array}{l}\text { Current (\%) } \\
\text { Ex-smoker (\%) }\end{array}$ & $14(29.2)$ & $18(26.9)$ & \\
\hline
\end{tabular}

NYHA New York Heart Association, HCM Hypertrophic cardiomyopathy

\section{Discussion}

This study sought to assess the prevalence and possible clinical implications of stress-induced myocardial perfusion defects on CMR in subjects with HCM. According to our results, stress-induced myocardial perfusion defects which reflect myocardial ischemia in the hypertrophied myocardium was a relatively frequent finding, and

Table 3 Comparison of Echocardiography and Other Lab Findings Between CMR Adenosine Stress-Positive and Negative Groups

\begin{tabular}{llll}
\hline & $\begin{array}{l}\text { Stress positive } \\
(n=48)\end{array}$ & $\begin{array}{l}\text { Stress } \\
\text { negative } \\
(n=67)\end{array}$ & $P$ value \\
\hline $\begin{array}{l}\text { Type of HCM } \\
\quad 17(35.4)\end{array}$ & $23(34.3)$ & 0.33 \\
$\quad$ Apeptal (\%) & $9(18.8)$ & $19(28.4)$ & \\
$\quad$ Septal+Apical (\%) & $14(29.2)$ & $18(26.9)$ & \\
$\quad$ Concentric (\%) & $8(16.7)$ & $5(7.5)$ & \\
$\quad$ Mixed (\%) & $0(0)$ & $2(3.0)$ & \\
$\begin{array}{l}\text { LV outflow } \\
\text { obstruction (\%) }\end{array}$ & $15(31.3)$ & $16(23.9)$ & 0.38 \\
$\begin{array}{l}\text { NSVT on 24-h holter } \\
\text { monitoring (\%) }\end{array}$ & $8 / 43(18.6)$ & $3 / 60(5.0)$ & 0.03 \\
$\begin{array}{l}\text { Inadequate blood pressure } \\
\text { response to exercise (\%) }\end{array}$ & $12 / 45(26.7)$ & $12 / 57(21.1)$ & 0.51 \\
$\begin{array}{l}\text { Exercise duration on stress } \\
\text { treadmill test (min:sec) }\end{array}$ & $9: 18 \pm 2: 21$ & $9: 51 \pm 2: 34$ & 0.30 \\
\hline
\end{tabular}

HCM Hypertrophic cardiomyopathy, LV Left ventricular; NSVT Nonsustained ventricular tachycardia 
Table 4 Comparison of CMR parameters between adenosine stress-positive and negative groups

\begin{tabular}{llll}
\hline Variables & $\begin{array}{l}\text { Stress positive } \\
(n=48)\end{array}$ & $\begin{array}{l}\text { Stress negative } \\
(n=67)\end{array}$ & $P$ value \\
\hline LVEF $(\%)$ & $71.7 \pm 7.4$ & $71.5 \pm 7.3$ & 0.34 \\
LV EDV $(\mathrm{ml})$ & $139.7 \pm 23.7$ & $138.3 \pm 29.5$ & 0.78 \\
LV ESV $(\mathrm{ml})$ & $39.4 \pm 11.5$ & $39.5 \pm 13.1$ & 0.99 \\
LV mass index $\left(\mathrm{g} / \mathrm{m}^{2}\right)$ & $98.0 \pm 30.9$ & $81.2 \pm 27.3$ & 0.003 \\
LGE (+) case, $\mathrm{n}$ & $45(93.8 \%)$ & $58(86.6 \%)$ & 0.21 \\
LGE volume $(\mathrm{ml})$ & $26.0 \pm 24.7$ & $15.6 \pm 15.6$ & 0.007 \\
LGE percentage $(\%)$ & $14.1 \pm 9.9$ & $9.9 \pm 7.6$ & 0.011 \\
Apical aneurysm, $\mathrm{n}$ & $10(20.8 \%)$ & $3(4.5 \%)$ & 0.006
\end{tabular}

LVEF Left ventricular ejection fraction, EDV End-diastolic volume, ESV Endsystolic volume, LGE Late gadolinium enhancement

was associated with various significant findings in HCM such as NSVT on 24-h ECG monitoring, apical aneurysm, and increased LV mass index. These findings arouse suspicion that microvascular dysfunction leading to stress-induced perfusion defects on CMR are significantly related to consequences that may lead to patient deterioration and sudden cardiac death in HCM. To our knowledge, this is the largest study its kind, and may elucidate the importance of evaluating microvascular dysfunction in this patient population.

The significance of microvascular dysfunction in HCM has been a subject of interest since the early days of the description of the disease [2-4]. According to previous reports, microvascular dysfunction and resulting myocardial ischemia may be of utmost importance in understanding the natural course of the disease and risk stratification for high-risk subjects for sudden cardiac death [4]. It has also been noted that assessment of myocardial ischemia may be crucial in evaluating subjects with HCM [6]. A recent study reported that

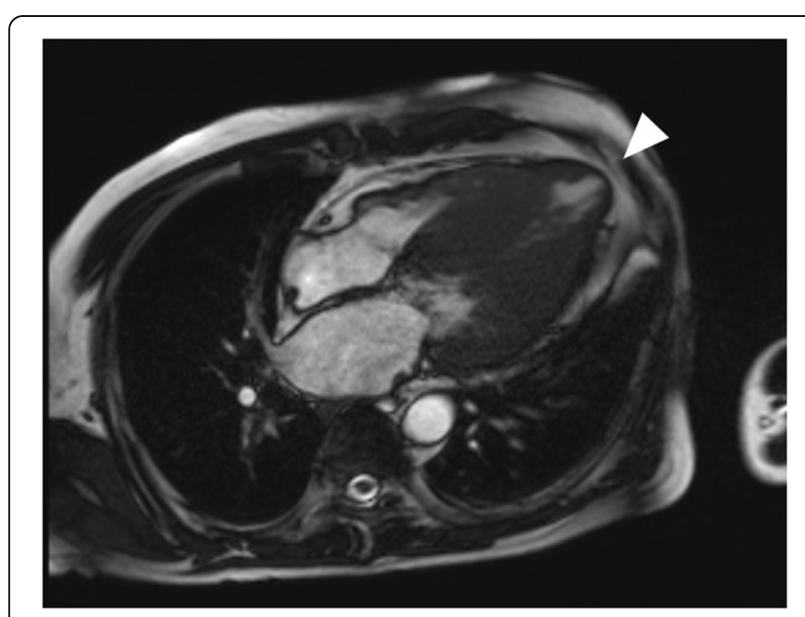

Fig. 4 Apical aneurysm on 4-chamber long axis cine CMR (arrowhead) detected on the same patient on Fig. 3
Table 5 Multivariate analysis of clinical and CMR findings between the stress-positive and negative groups

\begin{tabular}{lll}
\hline Variables & OR (95\% Confidence Interval) & $\boldsymbol{P}$ value \\
\hline Age & $0.98(0.95-1.01)$ & 0.233 \\
Gender, male vs. female & $0.12(0.03-0.58)$ & 0.008 \\
History of diabetes & $1.90(0.15-20.6)$ & 0.598 \\
History of smoking & 0.21 & \\
$\quad$ Ex-smoker & $1.23(0.36-4.22)$ & 0.740 \\
$\quad$ Current smoker & $0.75(0.21-2.71)$ & 0.657 \\
Atypical chest pain & $0.30(0.06-1.53)$ & 0.148 \\
History of syncope & $1.95(0.29-12.9)$ & 0.490 \\
NSVT on 24-h holter & $6.38(1.03-39.6)$ & 0.047 \\
Inadequate blood pressure & $0.66(0.18-2.36)$ & 0.523 \\
response to exercise & & 0.102 \\
LV outflow tract obstruction & $0.32(0.08-1.26)$ & 0.036 \\
Presence of apical aneurysm & $5.58(1.12-27.7)$ & 0.946 \\
LGE volume & $0.99(0.97-1.03)$ & 0.022 \\
\hline LV mass index & $1.03(1.01-1.06)$ &
\end{tabular}

$O R$ Odds ratio. $P$ value were calculated with multiple logistic regression $L V$ Left ventricular, NSVT Non-sustained ventricular tachycardia, LGE Late gadolinium enhancement

microvasculopathy may be an intrinsic feature of HCM with similar characteristics across the natural phases of the disease, and suggested that this may induce prolonged intramyocardial ischemia resulting in extensive scar formation and consequent end-stage evolution [28]. However, few investigations have been performed in this area and stress-induced myocardial perfusion defects have not been established as a possible clinical risk factor or target of management. Furthermore, even fewer reports have been published on the prevalence of myocardial ischemia or stress-induced perfusion defects in HCM $[29,30]$, and they have utilized nuclear imaging methods only.

CMR has been shown to be a highly sensitive method for assessing myocardial perfusion abnormalities not only in patients with coronary artery disease, but also in subjects with microvascular dysfunction [15, 16, 31, 32]. Utilization of this method in addition to plain LGE imaging in CMR may be a useful way to evaluate the microvascular dysfunction associated with HCM or other myopathic processes. There have been a few reports on stress-induced myocardial perfusion defects detected by CMR in patients with HCM [8, 33-35], but no large-scaled studies have demonstrated the clinical characteristics or significance of the finding in detail.

There have been previous reports associating microvascular dysfunction depicted by stress-induced myocardial perfusion abnormalities on nuclear studies in HCM with clinical deterioration or death $[4,36]$. In agreement with prior investigations which showed reduced 

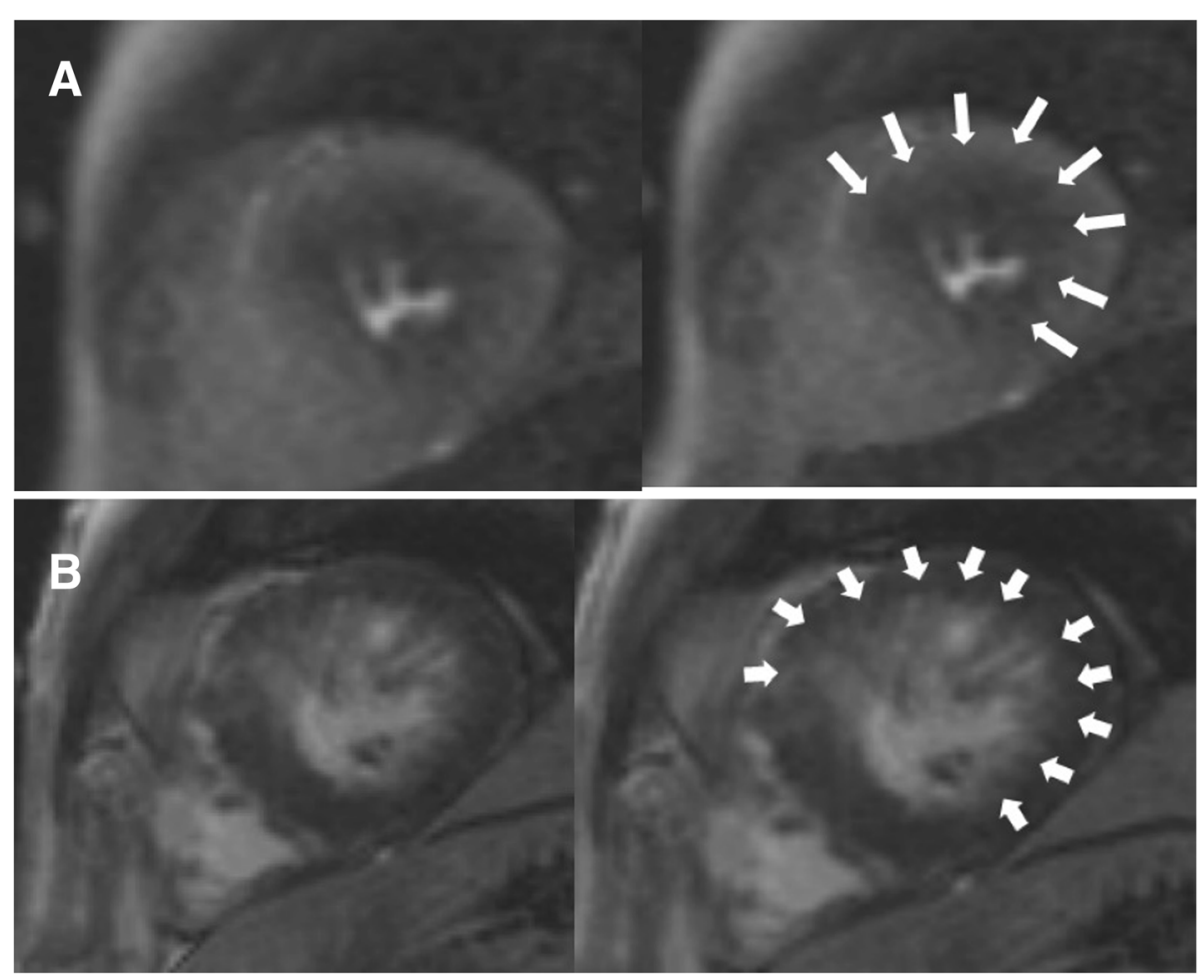

Fig. 5 Example of adenosine-stress induced perfusion defect (a, long arrows) that overlapped with the site of LGE (b, short arrows). This subject was categorized as adenosine-stress CMR negative

myocardial perfusion reserve in HCM being correlated with the magnitude of hypertrophy [4, 7], our data demonstrated a significant association between the stressperfusion defect and LV mass index. In addition, NSVT on holter and apical aneurysm which were risk factors for poor prognosis in HCM were also associated with stress perfusion defect on CMR. The fact that NYHA class, exercise duration, or history of syncope did not show significant correlation with stress-perfusion defect in our data may have been due to the fact that the subjects enrolled in our study were mostly asymptomatic or had mild symptoms and the proportion of subjects with substantial symptoms were too small to show any significant results. Taken together, there have been notions that CMR stress perfusion analysis may have utility in predicting prognosis and risk stratification [37], but as the associations of stress-induced perfusion defects on CMR with the above findings do not directly indicate that the perfusion defect is a significant independent risk factor or prognostic indicator in HCM at this time, further prospective studies may be needed to evaluate the clinical value of stressinduced perfusion defects on CMR.

We found female patients had stress-perfusion defects more frequently. Although not proven in any large-scale studies, microvascular dysfunction without significant epicardial coronary artery disease is thought to be more prevalent in women $[38,39]$, but this is the first time it has been demonstrated in HCM subjects. However, as the number and proportion of women in this study are relatively small, further studies are needed to confirm this relationship. Meanwhile, as various previous reports indicate that women with HCM show a more adverse prognosis $[40,41]$, this may be an interesting subject to pursue in future studies.

In comparison with the previous studies, our patients showed a higher prevalence of LGE on CMR.The prevalence of myocardial LGE in patients with HCM has been reported to vary from 33 to $84 \%$ [42-44]. Those reports commented that considering the heterogeneity of inclusion criteria for patient groups and scar pattern in HCM, such a wide range of reported incidence was not surprising. In our study, we included LGE that show focal, patchy or diffuse patterns in the right ventricular insertion site of interventricular septum as well as the mid-ventricular and epicardial wall, and the presence of myocardial fibrosis may have shown to be more frequent compared to other studies which enrolled limited LGE patterns in the mid-ventricular and epicardial wall only. We also believe that the classification of small focal hyperenhancements as significant LGE may have resulted in a higher incidence of LGE compared to other studies. 
Of note is caution in evaluating the stress-induced perfusion defects on CMR. As the stress perfusion test in CMR is performed before delayed image acquisition for LGE analysis, it is well known that the first-pass perfusion defect at the time of the initial contrast injection may also be related to the presence of massive fibrosis of the lesion and may correspond to the site of LGE. As this is the case, we carefully omitted the lesions that overlapped with the LGE (Fig. 5) and only included the defects that were not related to the LGE site. As this was the case, the findings on the quantitative analysis of the stress-perfusion defects showing significant difference in MPRI between the stress-positive group and the no perfusion defect group should be acknowledged, leaving out the analysis performed for the perfusion-defectcorresponding-to-LGE-site group.

\section{Study limitations}

Our study has some limitations. Firstly, only a proportion $(31 \%)$ of the study subjects that showed perfusion defects on stress CMR received invasive coronary angiography or coronary computed tomography angiography within 3 months of the CMR, although all of them showed normal or insignificant results. Hence, the coexistence of epicardial coronary artery disease cannot be completely excluded. However, the stress-induced perfusion defects did not correspond to a coronary artery territory, and subjects who showed significant ECG changes on the symptom-limited treadmill exercise ECG tests performed in about $90 \%$ of the subjects were all excluded. Furthermore, coronary artery disease cannot account for the perfusion defect rate of $40 \%$ in Korean patients with a mean age of 50. Secondly, 24-h ECG monitoring and treadmill exercise ECG were performed in most, but not in all subjects. However, subjects who did not undergo these tests were very few, and the proportion of the subjects who did not receive the test was similar between the stress-positive and negative groups, this limitation may not be critical to our analysis. Lastly, parametric mapping data could not be analyzed as the CMR in our study was performed before parametric mapping was incorporated into wide clinical use. Future studies using native T1 mapping and extracellular volume may be warranted to obtain additional information on the association between myocardial ischemia and LGE.

\section{Conclusions}

Adenosine-stress-induced perfusion defects on CMR are frequently found in subjects with HCM. The finding is associated with increased LV mass index, presence of apical aneurysm, and inadequate hemodynamic response to exercise. The clinical significance and prognostic value of the finding need further elucidation.

\section{Abbreviations}

CMR: Cardiovascular magnetic resonance; ECG: Electrocardiogram; EDV: Enddiastolic volume; ESV: End-systolic volume; HCM: Hypertrophic cardiomyopathy; LGE: Late gadolinium enhancement; LV: Left ventricle/left ventricular; LVEF: Left ventricular ejection fraction; LVOT: Left ventricular outflow tract; MPRI: Myocardial perfusion ratio index; NSVT: Non-sustained ventricular tachycardia; NYHA: New York Heart Association

\section{Acknowledgements}

We sincerely thank Dr. Jeanette Schulz-Menger for her continuous support for our research efforts.

\section{Authors' contributions}

All authors participated in the discussion of the concept of the study. SCL conceived the study design. EKK, SCL, SMK and YHC obtained CMR images and analyzed CMR scans. SAC, SYJ, SJP, JOC, SWP and ESJ analyzed data and drafted the manuscript with critical revision. As authors, we attest to each of our substantial contributions to the manuscript and revision. All authors read and approved the final manuscript.

Funding

None.

Availability of data and materials

The datasets used and/or analyzed during the current study are available from the corresponding author on reasonable request.

\section{Ethics approval and consent to participate}

The study design was approved by the local ethics committee and conducted according to the Declaration of Helsinki. Written informed consent was obtained from all study participants.

\section{Consent for publication}

All authors approved the manuscript and are aware of the data.

\section{Competing interests}

None.

Received: 7 August 2019 Accepted: 7 April 2020

Published online: 04 May 2020

\section{References}

1. Nishimura RA, Holmes DR Jr. Clinical practice. Hypertrophic obstructive cardiomyopathy. N Engl J Med. 2004;350:1320-7.

2. Camici P, Chiriatti G, Lorenzoni R, Bellina RC, Gistri R, Italiani G, et al. Coronary vasodilation is impaired in both hypertrophied and nonhypertrophied myocardium of patients with hypertrophic cardiomyopathy: a study with nitrogen-13 ammonia and positron emission tomography. J Am Coll Cardiol. 1991;17:879-86.

3. Lorenzoni R, Gistri R, Cecchi F, Olivotto I, Chiriatti G, Elliott P, et al. Coronary vasodilator reserve is impaired in patients with hypertrophic cardiomyopathy and left ventricular dysfunction. Am Heart J. 1998;136: 972-81

4. Cecchi F, Olivotto I, Gistri R, Lorenzoni R, Chiriatti G, Camici PG. Coronary microvascular dysfunction and prognosis in hypertrophic cardiomyopathy. N Engl J Med. 2003;349:1027-35.

5. Youn HJ, Park CS, Shin JW, Ihm SH, Cho EJ, Jung HO, et al. Estimation of flow reserve capacity of penetrating intramyocardial coronary arteries in apical hypertrophic cardiomyopathy: study using transthoracic Doppler echocardiography. Korean Circ J. 2004;34:271-9.

6. Maron MS, Olivotto I, Maron BJ, Prasad SK, Cecchi F, Udelson JE, et al. The case for myocardial ischemia in hypertrophic cardiomyopathy. J Am Coll Cardiol. 2009;54:866-75.

7. Petersen SE, Jerosch-Herold M, Hudsmith LE, Robson MD, Francis JM, Doll $\mathrm{HA}$, et al. Evidence for microvascular dysfunction in hypertrophic cardiomyopathy: new insights from multiparametric magnetic resonance imaging. Circulation. 2007;115:2418-25.

8. Ismail TF, Hsu LY, Greve AM, Goncalves C, Jabbour A, Gulati A, et al. Coronary microvascular ischemia in hypertrophic cardiomyopathy - a pixelwise quantitative cardiovascular magnetic resonance perfusion study. J Cardiovasc Magn Reson. 2014;16:49. 
9. Moon JC, McKenna WJ, McCrohon JA, Elliott PM, Smith GC, Pennell DJ. Toward clinical risk assessment in hypertrophic cardiomyopathy with gadolinium cardiovascular magnetic resonance. J Am Coll Cardiol. 2003;41: 1561-7.

10. Amano Y, Takayama M, Takahama K, Kumazaki T. Delayed hyperenhancement of myocardium in hypertrophic cardiomyopathy with asymmetrical septal hypertrophy: comparison with global and regional cardiac MR imaging appearances. J Magn Reson Imaging. 2004;20:595-600.

11. Knaapen P, van Dockum WG, Bondarenko O, Kok WE, Gotte MJ, Boellaard R, et al. Delayed contrast enhancement and perfusable tissue index in hypertrophic cardiomyopathy: comparison between cardiac MRI and PET. J Nucl Med. 2005;46:923-9.

12. Debl K, Djavidani B, Buchner S, Lipke C, Nitz W, Feuerbach S, et al. Delayed hyperenhancement in magnetic resonance imaging of left ventricular hypertrophy caused by aortic stenosis and hypertrophic cardiomyopathy: visualisation of focal fibrosis. Heart. 2006;92:1447-51.

13. Kwon DH, Smedira NG, Rodriguez ER, Tan C, Setser R, Thamilarasan M, et al. Cardiac magnetic resonance detection of myocardial scarring in hypertrophic cardiomyopathy: correlation with histopathology and prevalence of ventricular tachycardia. J Am Coll Cardiol. 2009;54:242-9.

14. Nagueh SF, Bierig SM, Budoff MJ, Desai M, Dilsizian V, Eidem B, American Society of Echocardiography, American Society of Nuclear Cardiology, Society for Cardiovascular Magnetic Resonance, Society of Cardiovascular Computed Tomography, et al. American Society of Echocardiography clinical recommendations for multimodality cardiovascular imaging of patients with hypertrophic cardiomyopathy: Endorsed by the American Society of Nuclear Cardiology, Society for Cardiovascular Magnetic Resonance, and Society of Cardiovascular Computed Tomography. J Am Soc Echocardiogr. 2011;24:473-98.

15. Ibrahim T, Nekolla SG, Schreiber K, Odaka K, Volz S, Mehilli J, et al. Assessment of coronary flow reserve: comparison between contrastenhanced magnetic resonance imaging and positron emission tomography. J Am Coll Cardiol. 2002;39:864-70.

16. Paetsch I, Jahnke C, Wahl A, Gebker R, Neuss M, Fleck E, et al. Comparison of dobutamine stress magnetic resonance, adenosine stress magnetic resonance, and adenosine stress magnetic resonance perfusion. Circulation. 2004; 110:835-42.

17. Rieber J, Huber A, Erhard I, Mueller S, Schweyer M, Koenig A, et al. Cardiac magnetic resonance perfusion imaging for the functional assessment of coronary artery disease: a comparison with coronary angiography and fractional flow reserve. Eur Heart J. 2006;27:1465-71.

18. Panting JR, Gatehouse PD, Yang GZ, Grothues F, Firmin DN, Collins P, et al. Abnormal subendocardial perfusion in cardiac syndrome $X$ detected by cardiovascular magnetic resonance imaging. N Engl J Med. 2002;346:1948-53.

19. Gersh BJ, Maron BJ, Bonow RO, Dearani JA, Fifer MA, Link MS, American College of Cardiology Foundation/American Heart Association Task Force on Practice Guidelines, American Association for Thoracic Surgery, American Society of Echocardiography, American Society of Nuclear Cardiology, Heart Failure Society of America, Heart Rhythm Society, Society for Cardiovascular Angiography, Interventions, Society of Thoracic Surgeons, et al. 2011 ACCF/ AHA guideline for the diagnosis and treatment of hypertrophic cardiomyopathy: a report of the American College of Cardiology Foundation/American Heart Association task force on practice guidelines. Circulation. 2011;124:e783-831.

20. Bettencourt N, Chiribiri A, Schuster A, Ferreira N, Sampaio F, Duarte R, et al. Cardiac magnetic resonance myocardial perfusion imaging for detection of functionally significant obstructive coronary artery disease: a prospective study. Int J Cardiol. 2013;168:765-73.

21. Lang RM, Bierig M, Devereux RB, Flachskampf FA, Foster E, Pellikka PA, et al. Recommendations for chamber quantification: a report from the American Society of Echocardiography's guidelines and standards committee and the chamber quantification writing group, developed in conjunction with the European Association of Echocardiography, a branch of the European Society of Cardiology. J Am Soc Echocardiogr. 2005;18:1440-63.

22. Ishimori ML, Martin R, Berman DS, Goykhman P, Shaw LJ, Shufelt C, et al. Myocardial ischemia in the absence of obstructive coronary artery disease in systemic lupus erythematosus. JACC Cardiovasc Imaging. 2011:4:27-33.

23. Bhave NM, Freed BH, Yodwut C, Kolanczyk D, Dill K, Lang RM, et al. Considerations when measuring myocardial perfusion reserve by cardiovascular magnetic resonance using regadenoson. J Cardiovasc Magn Reson. 2012:14:89.
24. Neubauer S, Kolm P, Ho CY, Kwong RY, Desai MY, Dolman SF, et al. Distinct subgroups in hypertrophic cardiomyopathy in the NHLBI HCM registry. Am Coll Cardiol. 2019;74:2333-45.

25. Axelsson RA, Farhad $H$, Valente AM, Couce JP, Jefferies JL, Bundgaard $H$, et al. Prevalence and progression of late gadolinium enhancement in children and adolescents with hypertrophic cardiomyopathy. Circulation. 2018;138:782-92.

26. Smith BM, Dorfman AL, Yu S, Russell MW, Agarwal PP, Mahani MG, et al. Clinical significance of late gadolinium enhancement in patients< 20 years of age with hypertrophic cardiomyopathy. Am J Cardiol. 2014; 113:1234-9.

27. Iles LM, Ellims AH, Llewellyn H, Hare JL, Kaye DM, McLean CA, et al. Histological validation of cardiac magnetic resonance analysis of regional and diffuse interstitial myocardial fibrosis. Eur Heart J Cardiovasc Imaging. 2015;16:14-22.

28. Alberto F, Valentina A, Claudio R, lacopo O, Barbara C, Luciano P, et al. Histopathological comparison of intramural coronary artery remodeling and myocardial fibrosis in obstructive versus end-stage hypertrophic cardiomyopathy. Int J Cardiol. 2019;291:77-82.

29. O'Gara PT, Bonow RO, Maron BJ, Damske BA, Van Lingen A, Bacharach SL, et al. Myocardial perfusion abnormalities in patients with hypertrophic cardiomyopathy: assessment with thallium-201 emission computed tomography. Circulation. 1987;76:1214-23.

30. Sorajja P, Chareonthaitawee P, Ommen SR, Miller TD, Hodge DO, Gibbons RJ. Prognostic utility of single-photon emission computed tomography in adult patients with hypertrophic cardiomyopathy. Am Heart J. 2006;151: 426-35.

31. Lanza GA, Buffon A, Sestito A, Natale L, Sgueglia GA, Galiuto L, et al. Relation between stress-induced myocardial perfusion defects on cardiovascular magnetic resonance and coronary microvascular dysfunction in patients with cardiac syndrome X. J Am Coll Cardiol. 2008;51:466-72.

32. Yilmaz A, Athanasiadis A, Mahrholdt $H$, Voehringer M, Ong P, Hill S, et al. Diagnostic value of perfusion cardiovascular magnetic resonance in patients with angina pectoris but normal coronary angiograms assessed by intracoronary acetylcholine testing. Heart. 2010;96:372-9

33. Moral S, Fernandez-Friera L, Sanz J. Microvascular dysfunction in hypertrophic cardiomyopathy evaluated by cardiac magnetic resonance and computed tomography. Acta Cardiol. 2010;65:367-9.

34. Tyan CC, Armstrong S, Scholl D, Stirrat J, Blackwood K, El-Sherif O, et al. Stress hypoperfusion and tissue injury in hypertrophic cardiomyopathy: spatial characterization using high-resolution 3-tesla magnetic resonance imaging. Circ Cardiovasc Imaging. 2013;6:229-38.

35. Karamitsos TD, Dass S, Suttie J, Sever E, Birks J, Holloway CJ, et al. Blunted myocardial oxygenation response during vasodilator stress in patients with hypertrophic cardiomyopathy. J Am Coll Cardiol. 2013;61: 1169-76.

36. Kaimoto S, Kawasaki T, Kuribayashi T, Yamano M, Miki S, Kamitani T, et al. Myocardial perfusion abnormality in the area of ventricular septum-free wall junction and cardiovascular events in nonobstructive hypertrophic cardiomyopathy. Int J Cardiovasc Imaging. 2012;28:1829-39.

37. Kim HW, Klem I, Kim RJ. Detection of myocardial ischemia by stress perfusion cardiovascular magnetic resonance. Magn Reson Imaging Clin N Am. 2007;15:527-40.

38. Reis SE, Holubkov R, Conrad Smith AJ, Kelsey SF, Sharaf BL, Reichek N, et al. Coronary microvascular dysfunction is highly prevalent in women with chest pain in the absence of coronary artery disease: results from the $\mathrm{NHLBI}$ WISE study. Am Heart J. 2001;141:735-41.

39. Han SH, Bae JH, Holmes DR Jr, Lennon RJ, Eeckhout E, Barsness GW, et al. Sex differences in atheroma burden and endothelial function in patients with early coronary atherosclerosis. Eur Heart J. 2008;29:1359-69.

40. Olivotto I, Maron MS, Adabag AS, Casey SA, Vargiu D, Link MS, et al. Genderrelated differences in the clinical presentation and outcome of hypertrophic cardiomyopathy. J Am Coll Cardiol. 2005;46:480-7.

41. Geske JB, Ong KC, Siontis KC, Hebl VB, Ackerman MJ, Hodge DO, et al. Women with hypertrophic cardiomyopathy have worse survival. Eur Heart J. 2017:38:3434-40.

42. Radwa AN, Songtao L, Marcelo SN, Daniel PJ, Marc KH, Theodore PA, et al. The diagnosis of hypertrophic cardiomyopathy by cardiovascular magnetic resonance. J Cardiovasc Magn Reson. 2012;14:17.. 
43. Amgad M, Pejman R, Nicholas GS, Ke F, Kimi S, Oussama W, et al. Late gadolinium enhancement in patients with hypertrophic cardiomyopathy and preserved systolic function. J Am Coll Cardiol. 2018;72:857-70.

44. Pedro F, António MF, Edmundo A, Murrilo OA, João $M$, João $A$, et al. The amount of late gadolinium enhancement outperforms current guidelinerecommended criteria in the identification of patients with hypertrophic cardiomyopathy at risk of sudden cardiac death. J Cardiovasc Magn Reson. 2019;21:50.

\section{Publisher's Note}

Springer Nature remains neutral with regard to jurisdictional claims in published maps and institutional affiliations.

Ready to submit your research? Choose BMC and benefit from:

- fast, convenient online submission

- thorough peer review by experienced researchers in your field

- rapid publication on acceptance

- support for research data, including large and complex data types

- gold Open Access which fosters wider collaboration and increased citations

- maximum visibility for your research: over $100 \mathrm{M}$ website views per year

At $B M C$, research is always in progress.

Learn more biomedcentral.com/submissions 